\title{
The effect of silver nitrate addition on the properties of electrospun polycaprolactone membranes with potential application for electrical stimulation in tissue engineering
}

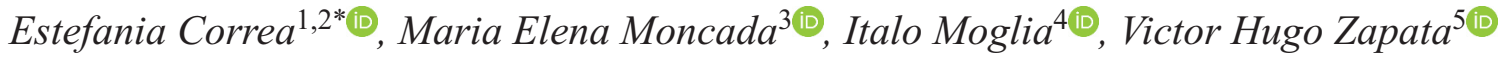 \\ ${ }^{1}$ Facultad de Ciencias Físicas y Matemáticas, Universidad de Chile, Santiago, Chile \\ ${ }^{2}$ Grupo de Investigación en Nuevas Tecnologías, Sostenibilidad e Innovación GINSTI, Universidad Francisco de Paula \\ Santander, Ocaña, Colombia \\ ${ }^{3}$ Grupo de Investigación en Materiales Avanzados y Energía MATyER, Instituto Tecnológico Metropolitano, Medellin, \\ Colombia \\ ${ }^{4}$ Facultad de Ciencias Químicas y Farmacéuticas, Universidad de Chile, Santiago, Chile \\ ${ }^{5}$ Grupo de Óxidos Avanzados, Universidad Nacional de Colombia, Medellín, Colombia
}

\begin{abstract}
The present work studies the effect of the addition of silver nitrate on the morphological, thermal, structural, mechanical, and electrical conductivity properties of polycaprolactone- $\mathrm{AgNO}_{3}$ membranes obtained by electrospinning, with a potential application for electrical stimulation in tissue engineering. The pure PCL membrane presented beads and fine fibers, while the PCL- $\mathrm{AgNO}_{3}$ membranes presented bead-less and greater diameter fibers than the pure polymer. Polymer crystallinity was affected by the salt due to the formation of complexes between the ions and the polymer, which affects polymer chains organization. These changes in fiber morphology and polymer chain organization affected their mechanical properties, resulting in a greater Young's modulus and ultimate tensile strength with added salt. The ionic conductivity of the sample with $10 \%$ salt $\left(2.02 \cdot 10^{-3} \mathrm{~S} / \mathrm{m}\right)$ is close to the conductivity of cortical bone $\left(1.82 \cdot 10^{-3}-6.67 \cdot 10^{-3} \mathrm{~S} / \mathrm{m}\right)$, which indicates its potential application for electrical stimulation in bone tissue engineering.
\end{abstract}

Keywords: nanomaterials, fibers, electrospinning, silver nitrate, ionic conductivity

\section{Introduction}

Millions of patients suffer from bone defects caused by tumors, infections, traumas, or genetic disorders that lead to abnormal skeletal development. Although bone has self-regenerative properties, when the size of the defects is considerable, or the patient suffers from some disease, these defects cannot heal properly, becoming a clinical challenge. Grafts are used as repair elements from studies in tissue engineering [1]. Currently, autografts, allografts, and biomaterials are used in bone tissue engineering. Autografts are considered the 'gold standard' in clinical procedures; they are more effective for bone regeneration, promoting bone formation on the surface by direct bone union and inducing stem cell differentiation without an immune response [1]. However, autograft extraction requires surgical intervention, bringing a risk of infection or long-term pain, with a complication rate of between $13-30 \%[1,2]$. Other alternatives explored have been allografts, although there are immunological barriers to overcome, such as the risk of disease transmission and a shortage of donors $[1,3]$. Biomaterials capable of replacing autografts or allografts present a novel alternative. A biomaterial for tissue engineering must be three-dimensional, allowing for tissue integration and development while

*Corresponding author, e-mail: teacorream@gmail.com (C) BME-PT 
favoring exposed surface area over volume, increasing porosity. It must also support cell culture before being incorporated into the body or promote osteoinduction through growth factors, hormones, drugs, or physical stimuli. Finally, it must function physiologically and have the biodegradability and mechanical properties of the defect being treated $[1,4]$.

Electrospinning is a very simple method for producing micro- and nanofibers from different polymers. It is a versatile and low-cost technique that has attracted the attention of many researchers for producing high porosity, small pore size, and high surface area membranes. These membranes have applications in different areas such as drug delivery [5], food packaging [6], filter systems [7], sensors [8], and especially in tissue engineering since the characteristics of the membranes obtained by electrospinning are similar to the extracellular matrix of body tissues. Almost all tissues and organs in the body are synthesized and organized with micro- and nanoscale fibrous structures [9]. Electrospinning is a biomimetic approach to bone tissue engineering [9]. The electrical properties of bone have been extensively studied, suggesting that electromagnetic stimuli generated within the bone play an essential role in the control of the formation and remodeling processes $[1,4,10]$. The electrokinetic phenomenon explains electrical stimulation in the bone, which is due to the formation of a double electrostatic layer composed of a charged surface (proteins) and a diffuse layer with positive and negative ions (body fluid). The movement of this charged fluid generates an electrical current that creates a difference in potentials called the flow potential, charging the cell membrane and affecting intracellular cycles [10, 11]. Given the importance of electrical stimulation in bone regeneration, bone tissue engineering has involved conductive polymers, which can emulate these electrical properties $[1,4]$. Ionic conductive polymers are solid electrolytes whose electrical conduction property is due to the migration of salt or acid ions. It is a promising alternative to be applied in tissue engineering [12].

The main objective of this study is to use electrospinning to produce fibrous membranes of an ionic conductive polymer with characteristics, such as the extracellular matrix and electrical properties, for possible application of electrical stimulation in bone tissue engineering. Polycaprolactone (PCL) served as the base polymer, which has been extensively investigated for tissue engineering applications due to its slow degradation rate, good permeability, and biocompatibility [13]. Ionic conductive polymers exhibit rapid ion mobility only when they are above their glass transition temperature, where their polymeric segments can move, permitting ion mobility [12]. Consequently, PCL is an excellent candidate for the development of ionic conducting polymers for tissue engineering, considering that the body temperature $\left(36^{\circ} \mathrm{C}\right)$ is between the glass transition temperature $\left(-60^{\circ} \mathrm{C}\right)$ and melting temperature $\left(60^{\circ} \mathrm{C}\right)$. Furthermore, the PCL contains a Lewis base (ester group), leading to the formation of complexes with the salt [13].

Silver nitrate was the source of silver ions to obtain the ionic conductive polymer. Silver ions and silver compounds have been widely studied in the development of electrospun membranes for antimicrobials $[14,15]$, wound healing [16], and tissue engineering [17], among other purposes.

The addition of salts to a polymer solution can affect the electrospinning process. Although electrospinning is a simple method, its theoretical principles are complex, involving various academic fields such as electrostatics, electrohydrodynamics, rheology, and aerodynamics for understanding micro- and nanofiber formation from a starting polymer solution. The surface tension, viscoelasticity, and surface charge distribution of the solution play a crucial role in the electrospinning process $[18,19]$. Some researchers have reported that adding salts or surfactants can improve electrospinability and modulation of fiber morphology. Klairutsamee et al. [20] improved the electrospinability of polybutylene succinate (PBS) using the organic salt, alkyl ammonium ethyl sulfate (AAES). On the other hand, Arayanarakul et al. [19] studied the effect of various inorganic salts such as $\mathrm{NaCl}, \mathrm{LiCl}, \mathrm{KCl}, \mathrm{MgCl}_{2}$, and $\mathrm{CaCl}_{2}$ on the electrospinning of polyethylene glycol PEO solutions, finding that $\mathrm{NaCl}$ improves the morphology of the PEO fibers. The effect of adding salts to polymer solutions on the electrospinning process has been analyzed from different points of view. Some researchers indicate that the increased electrical conductivity of the polymer solution with salts induces a decrease in fiber diameter [19, 21-23]. In contrast, others suggest that increased electrostatic forces generate greater mass flow towards the jet, leading to an increase in fiber diameter [19, 24, 25]

Due to the important effect of the addition of salt on the electrospinning process, the present study 
evaluated how different concentrations of $\mathrm{AgNO}_{3}$ salt in PCL affected the morphological, thermal, structural, mechanical, and electrical conductivity properties of electrospun membranes and their potential application for electrical stimulation in bone tissue engineering, which has not been previously reported.

\section{Materials and methods}

Polycaprolactone $\left(M_{\mathrm{w}}=80000 \mathrm{~g} / \mathrm{mol}\right) \quad($ Sigma Aldrich, Saint Louis, MO, USA), silver nitrate ACS (Alfa Aesar, Ward Hill, MA, USA), and acetone 99\% (Merck), were used to produce membranes. The polymer, salt, solvent ratios, and electrospinning parameters were optimized to produce polymer-salt membranes. The same parameters were then used to produce a PCL membrane and thus evaluate the effect of salt on the different properties. The polymersalt-acetone solutions were prepared with a polymeracetone concentration of $3 \% \mathrm{w} / \mathrm{v}$ and salt-polymer (cation/monomer) molar ratios of 5, 7, 10, and 14\%. The polymer and the salt were dissolved in acetone separately. Subsequently, both solutions were mixed and stirred for $24 \mathrm{~h}$ to ensure homogeneity and formation of polymer-salt complexes. The membranes were produced using the FLUIDNATEKTM LE 100 BioInicia electrospinning system. The solution was placed in a $5 \mathrm{ml}$ syringe and operated with process parameters: $1 \mathrm{ml} / \mathrm{h}$ flow, $10 \mathrm{~cm}$ collector-tip distance, $10 \mathrm{kV}$ tip voltage, and $-15 \mathrm{kV}$ collector voltage.

The crystal structure of the membranes was studied using an XPert PANalytical Empyrean Series II Alpha1 X-ray Diffractometer (XRD) with a copper tube. The degree of crystallinity and the crystallite size of the phases present in each sample was estimated using EVA 2.0 Software. Differential scanning calorimetry was performed on 5-6 mg samples using an SDT Q600 TA Instruments calorimeter, with a nitrogen flow of $100 \mathrm{ml} / \mathrm{min}$ and a ramp of $5.00^{\circ} \mathrm{C} / \mathrm{min}$ up to $90.0^{\circ} \mathrm{C}$. Universal Analysis 2000 Software was used to obtain the melting enthalpies $\left(\Delta H_{\mathrm{f}}\right)$ and melting temperatures of each sample.

Fiber morphology was observed with a JEOL JSM7100 Scanning Electron Microscope (Field Emission Gun, FEG). The samples were previously coated with a thick layer of gold by a Sputtering Quorum Q300td. Fiber diameters were measured using ImageJ software for determining the average diameter and size distribution.

Tension tests were performed using a SHIMADZU Universal Machine Model AG-100NKX with a $500 \mathrm{~N}$ cell. Each sample was $7 \mathrm{~cm}$ long, $5 \mathrm{~mm}$ wide, and over $100 \mu \mathrm{m}$ thick. Each tensile test was performed with a calibrated length of $5 \mathrm{~cm}$ and $10 \mathrm{~mm} / \mathrm{min}$ speed. Five tests were carried out for each membrane.

Complex impedance spectroscopy tests were performed on the salt-containing membranes to evaluate their potential application for electrical stimulation in tissue engineering. Circles with a diameter of $1 \mathrm{~cm}$ were cut from each membrane. These were moistened in deionized water until their weight increased by $30 \%$ to simulate bone moisture. Impedance was measured using a HIOKI 3532-50 LCR HiTESTER impedance meter with an applied voltage of $1 \mathrm{~V}$, scanning from $42 \mathrm{~Hz}$ to $5 \mathrm{MHz}$. The membranes were placed between two gold electrodes of equal diameter in a temperature-controlled cell, scanning from 24 to $48^{\circ} \mathrm{C}$ in steps of $3{ }^{\circ} \mathrm{C}$.

The real impedance $Z^{\prime} v s$. the imaginary impedance $Z^{\prime \prime}$ of the samples was plotted. The intersection of the curve with the $\mathrm{X}$-axis represents the sample bulk resistance, which is necessary for calculating the ionic conductivity of the samples $(\sigma), \sigma=I / A \cdot 1 / R$ where $I$ is the thickness, $A$ is the cross-sectional area, and $R$ is the sample bulk resistance.

\section{Results and discussion}

\subsection{XRD analysis}

Figure 1 shows the diffraction patterns of the pure polymer and the PCL- $\mathrm{AgNO}_{3}$ samples. The XRD study of the microstructural properties of pure-PCL membranes indicates the existence of characteristic planes (110), (111), and (200) at 21.5, 22.1, and 23.8 $2 \theta$, respectively, due to the semi-crystalline structure of PCL $[26,27]$. The diffractograms of $\mathrm{AgNO}_{3}$ containing membranes, showing the peaks of planes

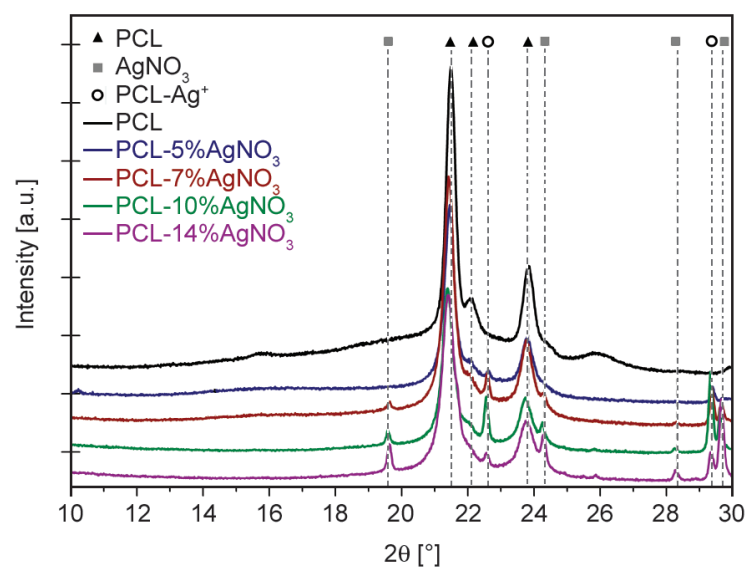

Figure 1. XRD patterns of the samples. 
(111), (102), (020), (021), (210), and (211) of the orthorhombic $\mathrm{AgNO}_{3}$ phase (PDF 043-0649). Additionally, the PCL- $\mathrm{AgNO}_{3}$ complex diffractograms show two unidentified peaks at 22.6 and $29.3^{\circ} 2 \theta$. This indicates that electrospinning effectively incorporates $\mathrm{AgNO}_{3}$ into the PCL structure and generates a new phase attributable to the interaction between the PCL matrix and $\mathrm{Ag}^{+}$dissolved cations (PCL- $\mathrm{Ag}^{+}$ complex). Zidan et al. [28] reported on the addition of $\mathrm{AgNO}_{3}$ in polyvinyl alcohol (PVA) films, indicating the existence of a new crystalline phase due to the PVA- $\mathrm{Ag}^{+}$complex, a result of the $\mathrm{Ag}^{+}$interacting with the $\mathrm{OH}$ group of the PVA.

The degree of crystallinity and the crystallite size of the phases in each sample, presented in Table 1, were estimated using EVA 2.0 Software.

The effects of adding salt to the polymer can be observed in the diffraction patterns of the samples (Figure 1). The polymer peaks shift slightly to the left when the salt is added, possibly due to the salt ions generating defects in the organization of the polymer chains and contributing to an increased interplanar distance.

A higher percentage of added salt leads to increased silver nitrate peak intensity, indicating a greater presence of silver crystals that crystallize in the electrospinning process. Also, $\mathrm{PCL}-\mathrm{Ag}^{+}$complex associated peaks increased in intensity with the addition of 5,7 , and $10 \%$ salt. With the addition of $14 \%$ salt, the formation of silver crystals was favored over the PCL- $\mathrm{Ag}^{+}$complex, which is reflected in the decreased intensity of the peaks associated with the latter.

\subsection{DSC analysis}

Figure 2 presents the DSC thermograms of the pure polymer and the PCL- $\mathrm{AgNO}_{3}$ samples. The DSC curves show endothermic peaks corresponding to the melting temperature of the polymer phases. A single endothermic peak is observed at around $57.6^{\circ} \mathrm{C}$ for the pure polymer, while the salt-added samples present undefined peaks, as well as a shoulder at a higher

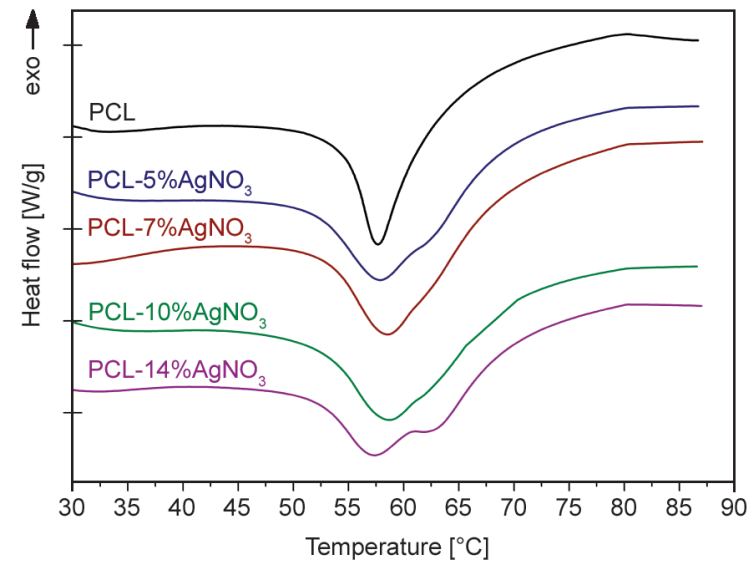

Figure 2. DSC thermograms of the samples.

temperature, which may indicate the superposition of two peaks.

The additional peak at a higher temperature of around $62{ }^{\circ} \mathrm{C}$ may be attributed to the polymer's PCL- $\mathrm{Ag}^{+}$complex melting point changing with the added salt. This result is consistent with the diffraction patterns in which undefined peaks were associated with the PCL- $\mathrm{Ag}^{+}$phase formation. Furthermore, the crystallite size of the PCL- $\mathrm{Ag}^{+}$phase is larger than that of the pure polymer, which is reflected in the higher temperature of the endothermic peak [29]. In particular, the thermogram of the $14 \%$-salt sample clearly shows the existence of two endothermic peaks. With $14 \%$ salt, the peak corresponding to the pure polymer is slightly displaced to a lower temperature than that of the other samples. Peak displacement is associated with a decrease in the crystallite size, as indicated in the diffraction results.

Table 1 presents the polymer phase melting enthalpies $\left(\Delta H_{\mathrm{f}}\right)$ and the central peak melting temperatures of the samples. The added-salt samples presented a higher enthalpy of fusion than the pure polymer, which is associated with an increase in the degree of crystallinity due to the formation of the PCL- $\mathrm{Ag}^{+}$ phase and the polymer chain organization generated by the presence of salt ions. Compared to the other samples, the $14 \%$-salt sample showed a reduced

Table 1. The degree of crystallinity and crystallite size; melting enthalpy $\left(\Delta H_{\mathrm{f}}\right)$ and the main peak melting temperature of the samples.

\begin{tabular}{|c|c|c|c|c|c|c|}
\hline Sample & $\begin{array}{c}\text { Crystallinity } \\
{[\%]}\end{array}$ & $\begin{array}{l}d_{\mathrm{PCL}} \\
{[\mathrm{nm}]}\end{array}$ & $\begin{array}{c}d_{\mathrm{AgNO}_{3}} \\
{[\mathrm{~nm}]}\end{array}$ & $\begin{array}{c}d_{\text {PCL-Ag }}{ }^{+} \\
{[\mathrm{nm}]}\end{array}$ & $\begin{array}{l}\Delta H_{\mathrm{f}} \\
{[\mathrm{J} / \mathrm{g}]}\end{array}$ & $\begin{array}{c}T_{\mathbf{m}} \\
{\left[{ }^{\circ} \mathbf{C}\right]}\end{array}$ \\
\hline PCL & 69.8 & 30.2 & - & - & 64.2 & 57.6 \\
\hline PCL-5\%AgNO 3 & 70.0 & 24.5 & 47.5 & - & 76.5 & 57.7 \\
\hline PCL-7\% $\% \mathrm{AgNO}_{3}$ & 73.8 & 24.5 & 66.8 & 70.0 & 76.3 & 58.3 \\
\hline PCL- $10 \% \mathrm{AgNO}_{3}$ & 86.0 & 24.5 & 69.5 & 62.5 & 76.2 & 58.4 \\
\hline PCL-14\% $\mathrm{AgNO}_{3}$ & 87.0 & 20.5 & 57.0 & 61.0 & 71.6 & 57.1 \\
\hline
\end{tabular}


increase in the fusion enthalpy, which indicates a relative decrease in the degree of crystallinity of the polymer phases.

\subsection{Morphological analysis}

Figure 3 presents the SEM micrographs of the pure polymer. Evidence of electrospray was indicated by the beads and fine fibers obtained when the PCL was electrospun [30]. The beads have an average size of $2090 \pm 40 \mathrm{~nm}$, while the fine fibers have a diameter of $98 \pm 1 \mathrm{~nm}$. The low concentration of the polymer in solution generated the obtained morphology [31]. SEM micrographs of the membranes with 5, 7, 10, and $14 \% \mathrm{AgNO}_{3}$ salt are presented in Figures 4 and 5. The average fiber diameter increased to $200 \mathrm{~nm}$ in the case of added salt and did not form beads when electrospun using the same parameters as resulted in bead formation for the pure polymer. The addition of salt has two effects on the electrospinning process. When the ion content of the solution is high, firstly

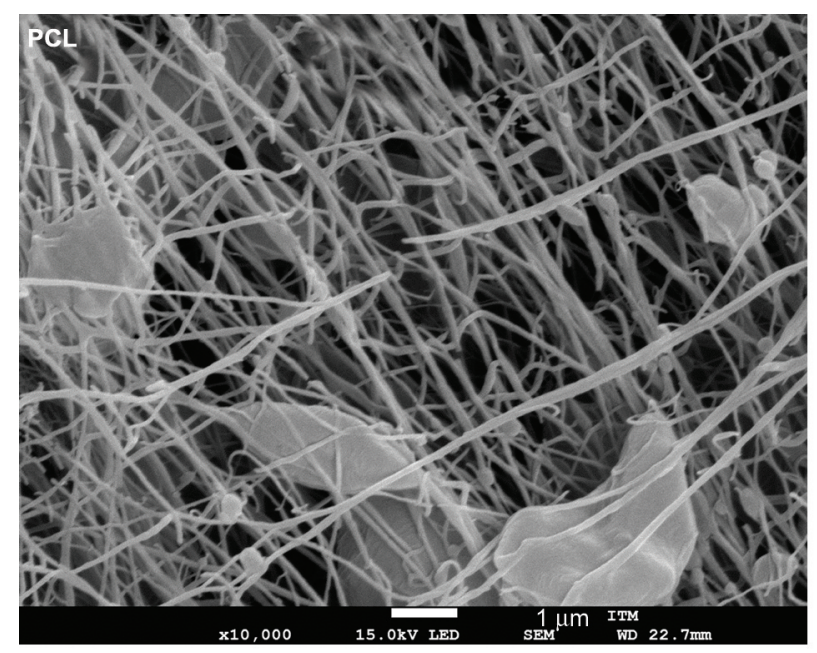

a)

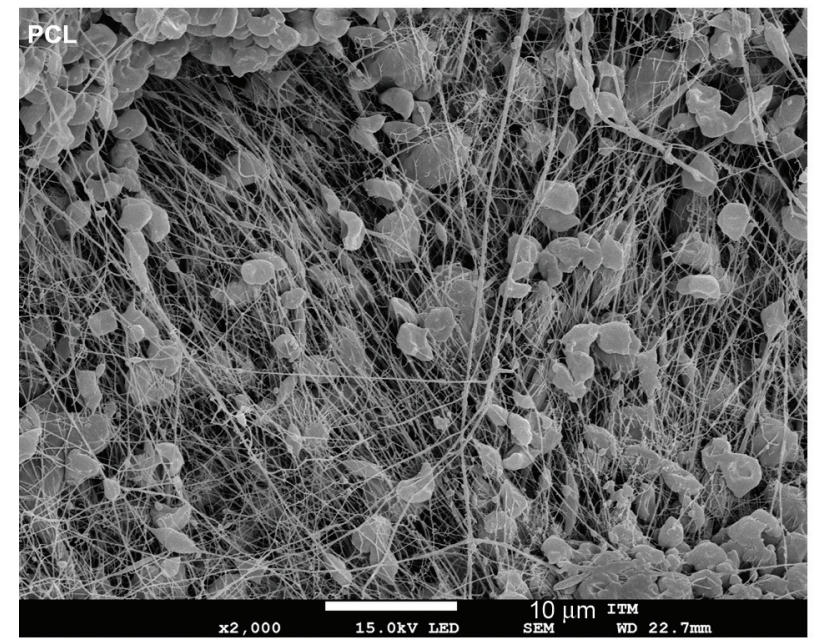

c) it increases the surface charge density and the electrostatic force generated by the electric field, and secondly, it increases the conductivity of the polymer solution, which may decrease the fiber diameter, according to some authors $[19,22,23]$. However, in the present work, the fiber diameter increased with the addition of salt. Some researchers have studied this effect, suggesting that the fiber diameter increases due to the greater mass flow towards the jet from the effect of salt on the electrostatic force [19, 24, 25]. The average fiber diameter increased from $184 \pm 2$ to $219 \pm 3 \mathrm{~nm}$ when raising the salt concentration from 5 to $7 \%$ due to the increased mass flow mentioned.

With $10 \%$ salt, the average fiber diameter was $221 \pm 2 \mathrm{~nm}$, similar to that of the $7 \%$ salt. This may indicate a balance between the increasing electric conductivity of the solution promoting thinner fibers and the increasing mass flow due to the internal electrostatic force promoting thicker fibers. Finally, with $14 \%$ salt, the fiber diameter decreased slightly to
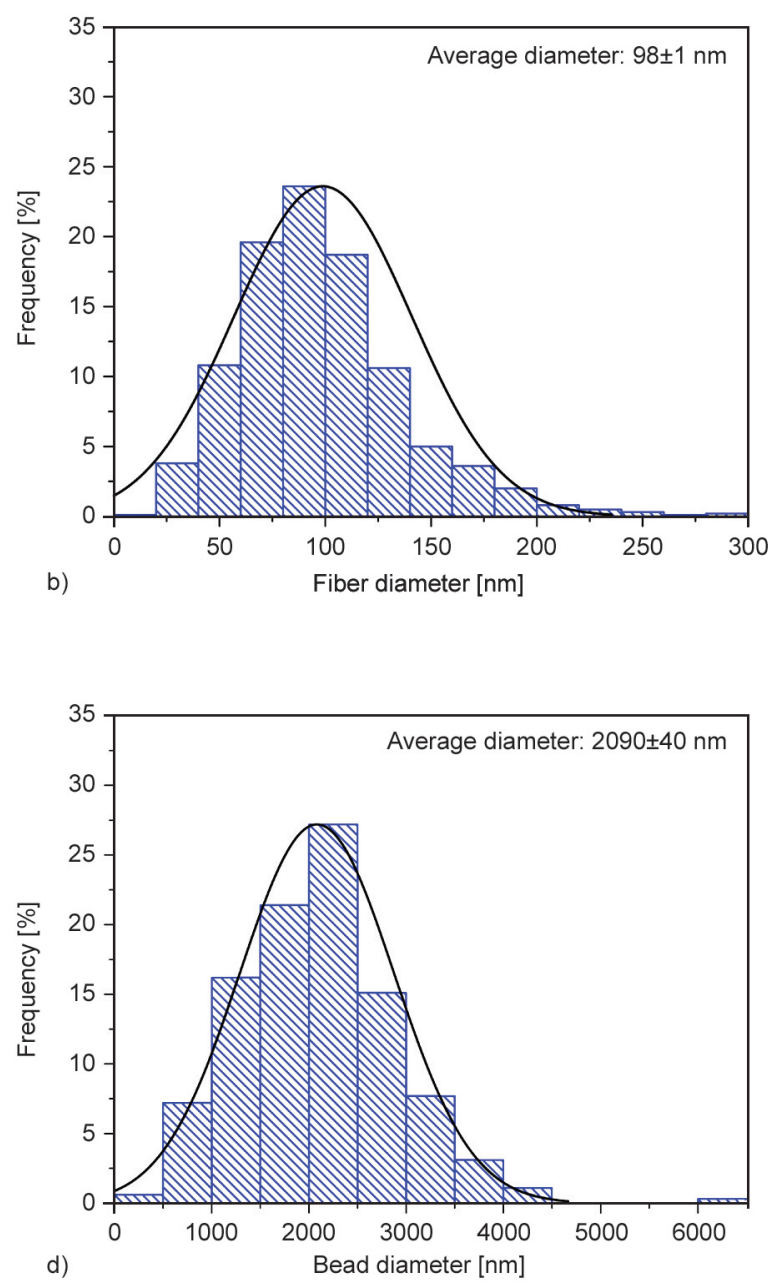

Figure 3. SEM micrographs and histograms of pure PCL sample. Fibers (a) and (b). Beads (c) and (d). 


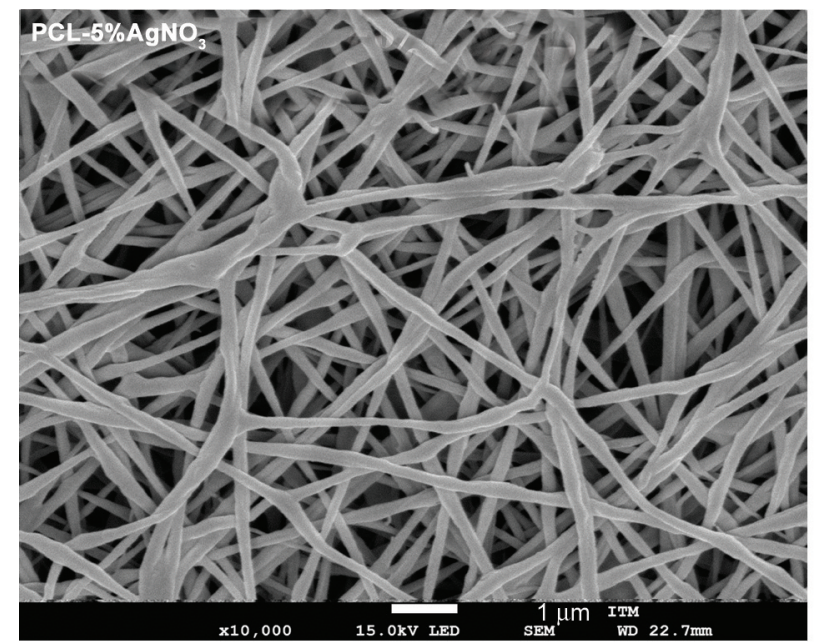

a)

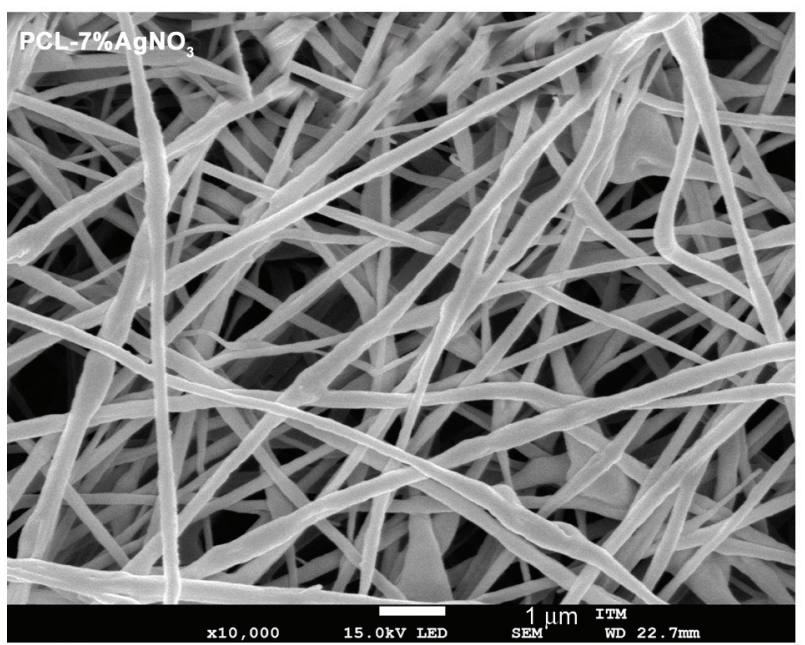

c)
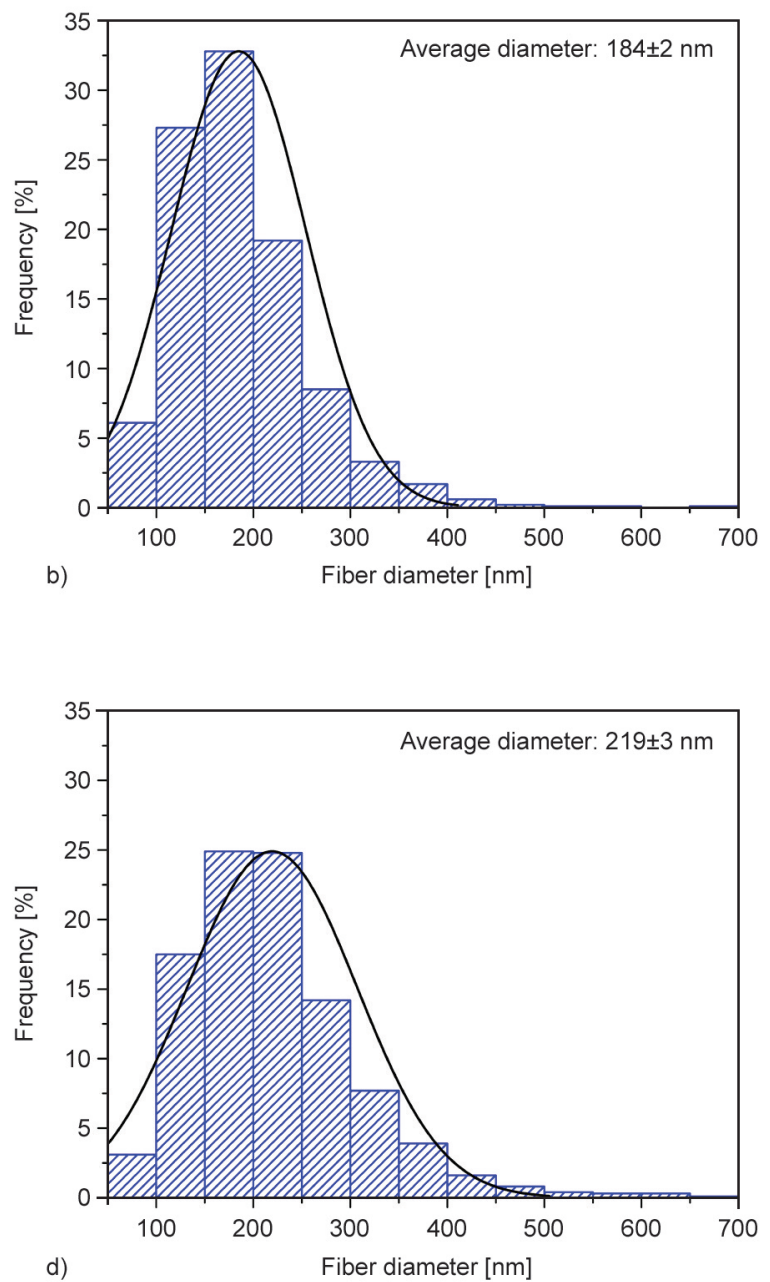

Fiber diameter [nm]

Figure 4. SEM micrographs and histograms of fiber diameter: PCL-5\% $\mathrm{AgNO}_{3}$ (a) and (b). PCL-7\% $\mathrm{AgNO}_{3}$ (c) and (d).

$200 \pm 3 \mathrm{~nm}$, indicating that the improved conductivity of the polymer solution dominates to reduce the fiber diameter. Solution properties, such as viscosity, surface tension, and conductivity, can also be measured in order to better understand the effect of salt addition on the electrospinning process.

The XRD results showed $\mathrm{AgNO}_{3}$ crystals in the membranes; however, these were not observed in SEM micrographs. The salt crystals may be inside the fibers. Fiber defects were noted. Branched fibers can be seen in Figure 5, which may be generated due to jet instabilities. The local charge per unit area from the salt content in the jet causes a smaller jet to splay from the surface of the primary jet, reducing the charge per unit area while producing two fibers of a smaller diameter, resulting in the observed branched fibers [32]. Also, fiber defects, such as varying diameters in a single fiber, are shown in Figure 5. A single fiber can have different diameters due to the instability in the jet generated by the mass flow towards it, as explained previously $[19,25]$.

\subsection{Mechanical properties}

The mechanical properties of the membranes produced by electrospinning depend on the morphology, diameters, uniformity, crystallinity, and chemistry of the fibers [33-36]. The porosity and poor uniformity of the fibers made the bonding within the web deficient and resulted in the loss of friction during load transfer between fibers, affecting the mechanical performance of the membranes, which explains why the mechanical properties of a polymer film are not comparable with an electrospun membrane of the same polymer [33]. Averous et al. [37] reported an extruded PCL film (80000 daltons) with a Young's modulus of $190 \pm 6 \mathrm{MPa}$, while electrospinning the same material with different solvents results in a Young's modulus of between 2.9 and $15.19 \mathrm{MPa}$ 


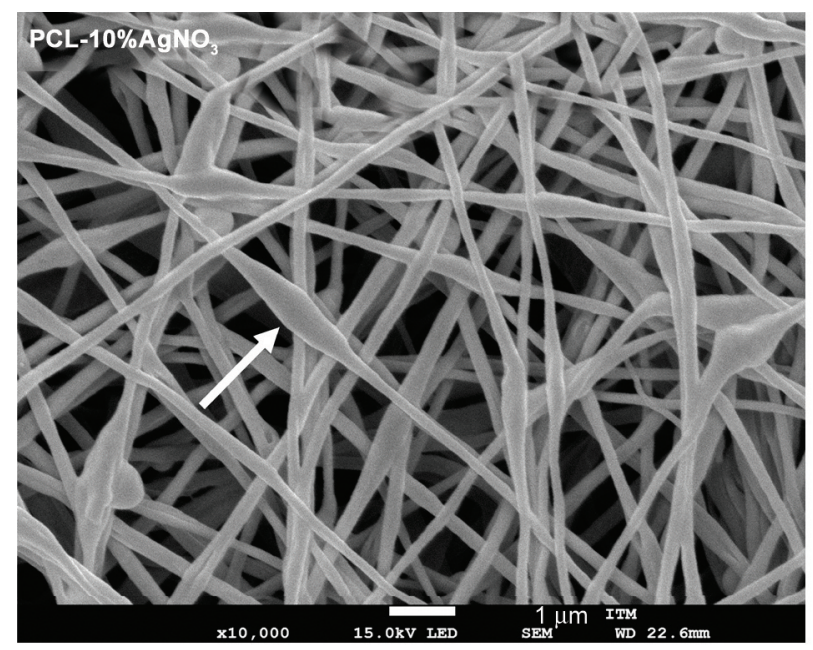

a)

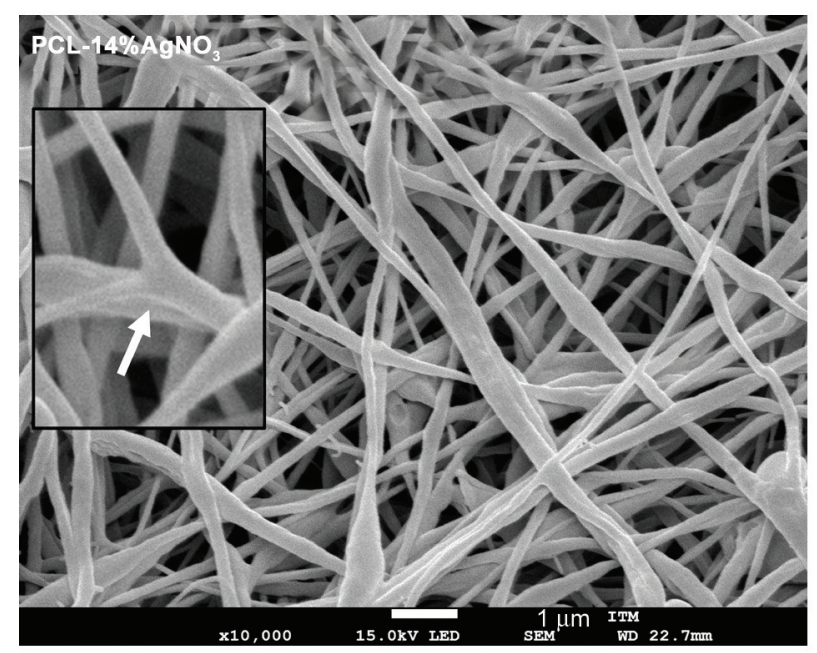

c)
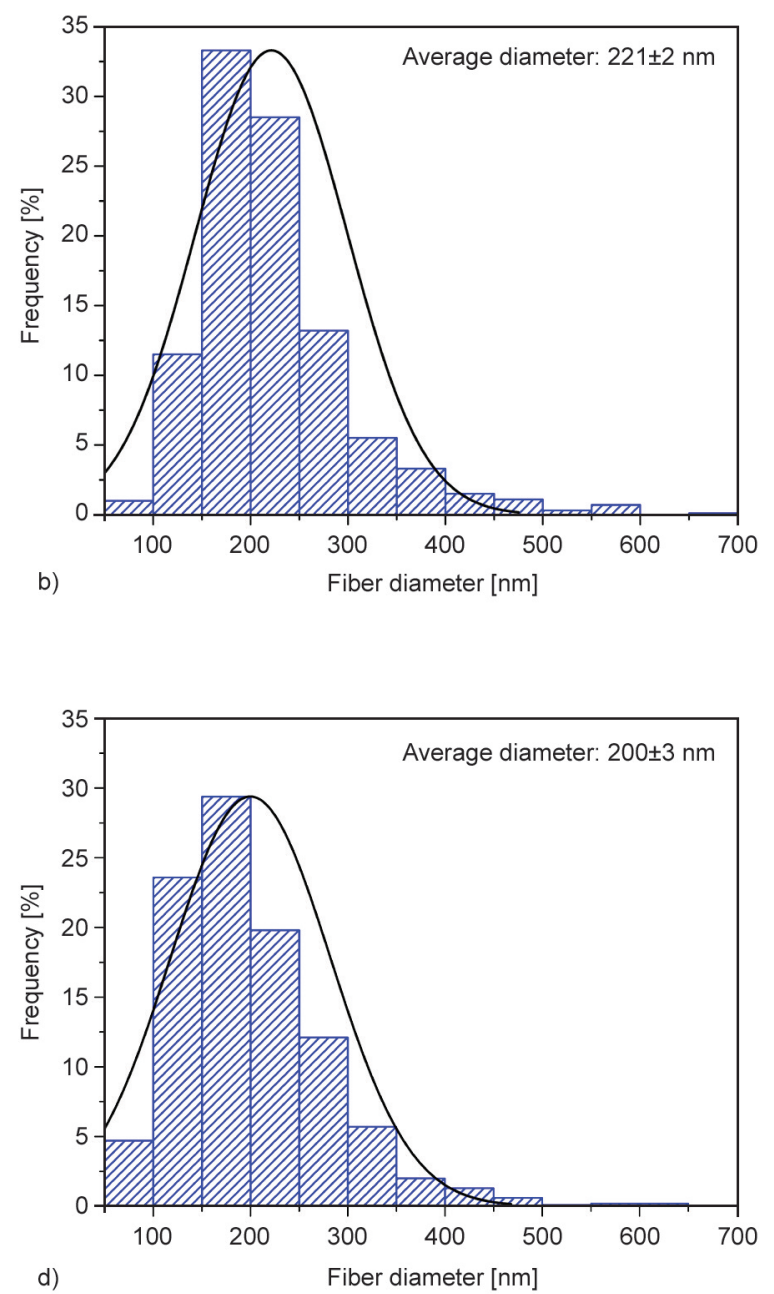

d)

3 (c) and (d).

implying less orientation of the polymer chain, which affects the crystalline arrangement and its mechanical performance [33, 40, 41, 43]. Other defects, such as branches and pores, generate non-uniform zones resulting in stress concentration during mechanical stretching and consequently becoming potential weak spots for failure to occur [33, 35, 45]. Similarly, the use of excessive filling does not act as an energy dissipator and, on the contrary, generates areas of stress concentration [33].

The curves in Figure 6 and data in Table 2 present the tensile testing results performed on the PCL $\mathrm{AgNO}_{3}$ membranes. The stress-strain curves exhibit elastic behavior with subsequent deformation without neck formation. No reduction of the transverse area was observed at the break. PCL- $\mathrm{AgNO}_{3}$ membranes have a Young's modulus and ultimate tensile strength of 9 to 15 times higher than that of the pure polymer.

Electron microscopy images of the PCL membranes without salt show the coexistence of fine fibers with 


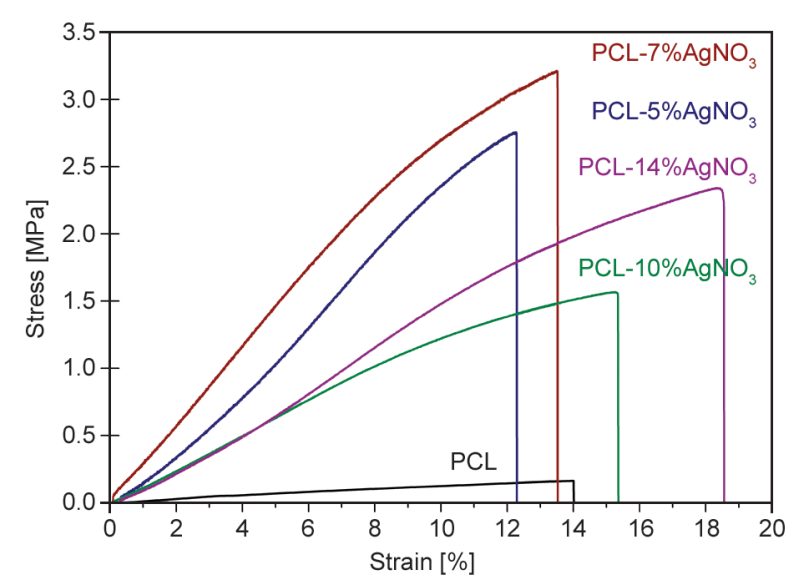

Figure 6. Stress-strain curves of the samples.

Table 2. Young's modulus, ultimate tensile strength, and strain-at-break of the samples.

\begin{tabular}{|c|c|c|c|}
\hline Samples & $\begin{array}{c}\text { Young's } \\
\text { modulus } \\
\text { [MPa] }\end{array}$ & $\begin{array}{c}\text { Ultimate } \\
\text { strength } \\
{[\mathrm{MPa}]}\end{array}$ & $\begin{array}{c}\text { Strain at } \\
\text { break } \\
{[\%]}\end{array}$ \\
\hline PCL & $1.9 \pm 0.4$ & $0.20 \pm 0.04$ & $14 \pm 1$ \\
\hline PCL-5\% $\% \mathrm{AgNO}_{3}$ & $28.0 \pm 6.0$ & $3.00 \pm 0.70$ & $14 \pm 3$ \\
\hline PCL-7\% $\% \mathrm{AgNO}_{3}$ & $28.0 \pm 3.0$ & $3.00 \pm 0.50$ & $13 \pm 2$ \\
\hline PCL- $10 \% \mathrm{AgNO}_{3}$ & $13.0 \pm 2.0$ & $1.70 \pm 0.20$ & $16 \pm 3$ \\
\hline PCL-14\%AgNO 3 & $18.0 \pm 1.0$ & $2.40 \pm 0.20$ & $17 \pm 3$ \\
\hline
\end{tabular}

beads, resulting in a high porosity material. In contrast, the membranes containing salt tend to produce a bead-free homogeneous size distribution of greater diameter fibers. The latter membranes exhibit Young's modulus of between 13-28 MPa, which is higher than some reports of electrospun polycaprolactone membranes $[38,39,46]$. This indicates that salt has a significant effect on the mechanical properties of PCL$\mathrm{AgNO}_{3}$ membranes. The electrostatic interactions generated between metallic ions and the polymer chains, the PCL- $\mathrm{Ag}^{+}$phases, and salt crystals may cause changes in the membrane's mechanical properties.

The analysis of the mechanical properties shows that the presence of silver nitrate increases Young's modulus and ultimate tensile strength. Low silver nitrate concentrations, such as $5-7 \%$, can act as fillers, strengthening fibers as energy dissipators [47-49]. However, a higher silver nitrate concentration of 10 $14 \%$ is detrimental to the Young's modulus and ultimate tensile strength due to the defects induced in the membrane microstructure and a larger silver nitrate crystal size, which can disrupt the energy dissipation $[47,48,50]$.

The deformation at break was around $15 \%$ for all membranes, which is less than that of some studies where they exceed $100 \%$ deformation $[38,39,46]$. This can be attributed to the decrease in the amorphous phase, the presence of salt crystals, the organization of the polymer chains, and the PCL- $\mathrm{Ag}^{+}$phase, which can affect the polymer chain stretching. The 10 and $14 \%$ salt samples had a slightly higher deformation at break than the 5 and $7 \%$ salt samples, which may be due to the defects observed in the fibers and the more significant presence of salt crystals. Therefore, the fibers have zones in which the jet was not lengthened correctly, implying less orientation of the polymer chain permitting higher deformation [44].

The Young's modulus obtained for all membranes with salt varies between 13 and $28 \mathrm{MPa}$, which is comparable to Young's modulus of trabecular bone, whose values vary between 10 and $2000 \mathrm{MPa}$ depending on the anatomical site and the age of the patient. On the other hand, the ultimate strength of the membranes was between 1.7 and $3.0 \mathrm{MPa}$, comparable to that of trabecular bone, between 0.5 and $100 \mathrm{MPa}$, depending on apparent density. Finally, the percentage of deformation for trabecular bone is close to $10 \%$, similar to that obtained from membranes with salt [51, 52].

\subsection{Ionic conductivity}

Despite the hydrophobic properties of PCL, the PCL$\mathrm{AgNO}_{3}$ membranes were moistened with deionized water, leading to an increase in weight. The silver salt ions present in crystal form and within the polymer complex can be solvated by water molecules [53].

Figure 7 presents the ionic conductivity results of the PCL-AgNO ${ }_{3}$ samples. The ionic conductivity in a solid electrolyte is due to salt ion mobility in the material, which can jump between the polymer coordination sites. On the other hand, salt crystal ions can also contribute to conductivity. In both cases, the presence of water improves the mobility of the ions [12]. The pure polymer did not exhibit conductivity and was therefore excluded. Figure 7 a presents the Real Impedance $Z^{\prime} v s$. Imaginary Impedance $Z^{\prime \prime}$ of the PCL-AgNO${ }_{3}$ membranes evaluated at $36^{\circ} \mathrm{C}$. The ionic conductivities of the membranes at different temperatures are shown in Figure $7 \mathrm{~b}$. The curves of 10 and $14 \%$ salt samples consist of two semicircles, one associated with bulk interactions and the other (incomplete) with the electrode-electrolyte surface interface. Similar behavior was found for the 5 and $7 \%$ salt samples; however, they are not within the chosen range. The center of the semicircle is below 

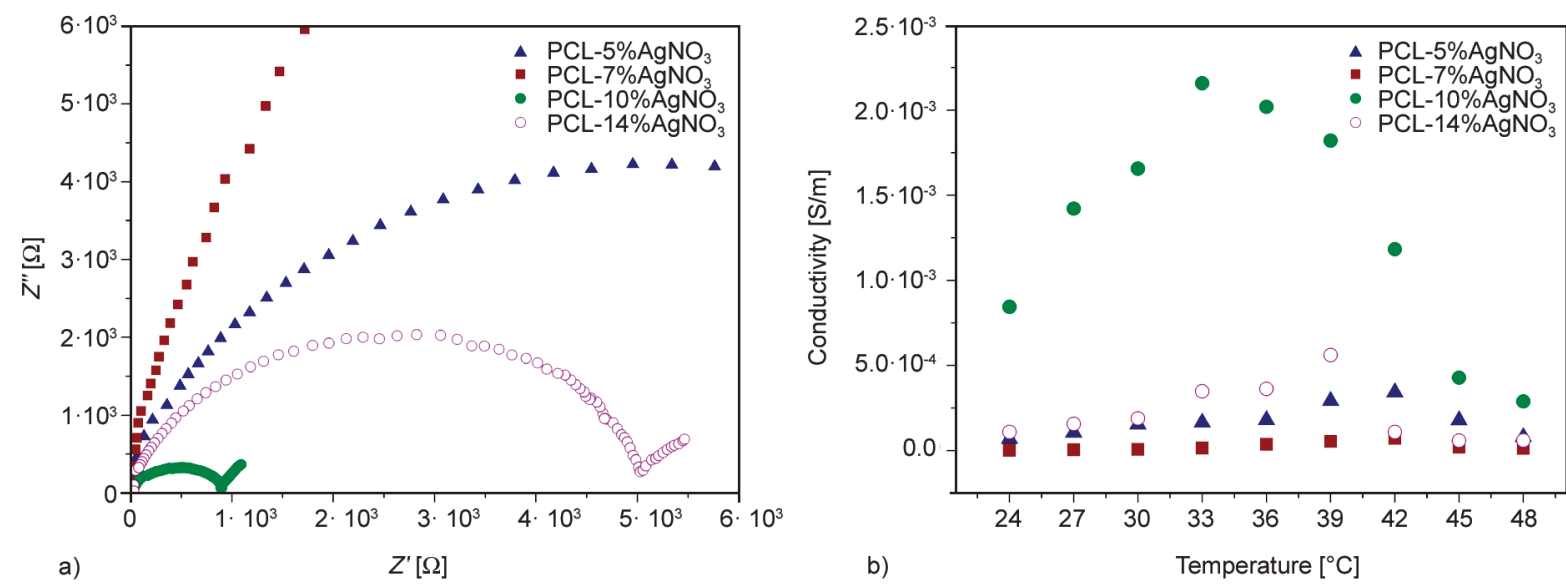

Figure 7. a) Real impedance $Z^{\prime} v s$. imaginary impedance $Z^{\prime \prime}$ at $36^{\circ} \mathrm{C}$ of the $\mathrm{PCL}-\mathrm{AgNO}_{3}$ samples and b) ionic conductivity $v s$. temperature of the PCL- $\mathrm{AgNO}_{3}$ samples.

the $\mathrm{X}$-axis for all samples due to the cation and anion dynamics during the frequency scan. However, this analysis was not carried out in this work. The $10 \%$ salt sample has a smaller diameter semicircle than the other samples, intercepting the $\mathrm{X}$-axis at around $1000 \mathrm{Ohms}$, which indicates that this sample has less resistance (higher conductivity) than the other samples. The $10 \%$ salt sample exhibited an increased intensity of the XRD peak associated with the PCL$\mathrm{Ag}^{+}$complex, indicating an increased presence of ions available to move through the structure and jump between coordination sites.

On the other hand, the $7 \%$ salt sample exhibits greater resistance compared to the other samples. This can be attributed to the formation of salt crystals in the membranes, restricting the mobility of the polymeric segments [12], which limits the mobility of the ions between the coordination sites. Finally, the $14 \%$ salt sample exhibited reduced conductivity, corresponding to the decreased intensity of the XRD peak associated with the PCL- $\mathrm{Ag}^{+}$complex, indicating fewer ions available to jump between coordination sites. The ionic conductivity of the $10 \%$ salt sample $\left(2.02 \cdot 10^{-3} \mathrm{~S} / \mathrm{m}\right)$ is close to the conductivity of cortical bone $\left(1.82 \cdot 10^{-3}-6.67 \cdot 10^{-3} \mathrm{~S} / \mathrm{m}\right)$, evidencing its potential application for electrical stimulation in bone tissue engineering [10].

Figure $7 \mathrm{~b}$ shows the ionic conductivity increases with temperature up to $33^{\circ} \mathrm{C}$ for the $10 \%$ salt sample and up to $39^{\circ} \mathrm{C}$ for the other samples. The energy supplied to the system by increasing the temperature promotes ion mobility since ionic conductivity is an activated process $[12,54]$. However, ionic conductivity decreases above $39^{\circ} \mathrm{C}$ due to the water, which is necessary for ion movement, evaporating from the membranes.

\section{Conclusions}

PCL- $\mathrm{AgNO}_{3}$ membranes were produced by electrospinning. The $\mathrm{XRD}$ results of the $\mathrm{PCL}-\mathrm{AgNO}_{3}$ membranes indicate the coexistence of polycaprolactone, silver nitrate crystal, and an additional phase attributed to the formation of a PCL- $\mathrm{Ag}^{+}$polymer-salt complex. The membranes containing salt showed an additional phase in the DSC results, coinciding with the XRD results. The pure PCL membrane presented beads and fine fibers, while the $\mathrm{PCL}-\mathrm{AgNO}_{3}$ membranes presented bead-less and greater diameter fibers compared to the pure polymer, despite being produced using the same parameters. However, defects such as branched fibers and variable diameters in a single fiber were observed with increased salt concentrations. The presence of the PCL- $\mathrm{Ag}^{+}$phase, the salt crystals, and the fiber defects affected the mechanical properties of the membranes. PCL- $\mathrm{AgNO}_{3}$ membranes have Young's modulus and ultimate tensile strength of between 9 and 15 times greater than those of the pure polymer. The 7\% salt sample had better mechanical properties but lower ionic conductivity than the other membranes. The ionic conductivity of the $10 \%$ salt sample $\left(2.02 \cdot 10^{-3} \mathrm{~S} / \mathrm{m}\right)$ is close to the conductivity of cortical bone $\left(1.82 \cdot 10^{-3}\right.$ $6.67 \cdot 10^{-3} \mathrm{~S} / \mathrm{m}$ ), evidencing its potential application for electrical stimulation in bone tissue engineering. 


\section{Acknowledgements}

The authors acknowledge the financial support received from Instituto Tecnológico Metropolitano at Medellín, Universidad Nacional de Colombia, Medellin, Scholarship Minciencias, Colombia - Doctorado en el exterior 2019, and Scholarship ANID, Chile - Doctorado Nacional 2018-folio 21182122.

\section{References}

[1] Leppik L., Oliveira K. M. C., Bhavsar M. B., Barker J. H.: Electrical stimulation in bone tissue engineering treatments. European Journal of Trauma and Emergency Surgery, 46, 231-244 (2020).

https://doi.org/10.1007/s00068-020-01324-1

[2] Bohner M.: Bone substitute materials. in 'Encyclopedia of biomedical engineering' (eds.: Wang M., Yu X., Laurencin C., Narayan R.) Elsevier, Amsterdam, Vol. 1, 513-529 (2019).

[3] Lyles M. B., Hu J. C., Varanasi V. G., Hollinger J. O., Athanasiou K. A.: Bone tissue engineering. in 'Regenerative engineering of musculoskeletal tissues and interfaces' (eds.: Nukavarapu S. P., Freeman J. W., Laurencin C. T.) Elsevier, Cambridge, 97-134 (2015). https://doi.org/10.1016/B978-1-78242-301-0.00005-7

[4] Khare D., Basu B., Dubey A. K.: Electrical stimulation and piezoelectric biomaterials for bone tissue engineering applications. Biomaterials, 258, 120280 (2020). https://doi.org/10.1016/j.biomaterials.2020.120280

[5] Luraghi A., Peri F., Moroni L.: Electrospinning for drug delivery applications: A review. Journal of Controlled Release, 334, 463-484 (2021).

https://doi.org/10.1016/j.jconrel.2021.03.033

[6] Mohammadi M. A., Hosseini S. M., Yousefi M.: Application of electrospinning technique in development of intelligent food packaging: A short review of recent trends. Food Science and Nutrition, 8, 4656-4665 (2020).

https://doi.org/10.1002/fsn3.1781

[7] al Mamun A., Blachowicz T., Sabantina L.: Electrospun nanofiber mats for filtering applications - Technology, structure and materials. Polymers, 13, 1368 (2021). https://doi.org/10.3390/polym13091368

[8] Zhang S., Jia Z., Liu T., Wei G., Su Z.: Electrospinning nanoparticles-based materials interfaces for sensor applications. Sensors, 19, 3977 (2019). https://doi.org/10.3390/s19183977

[9] Rahmati M., Mills D. K., Urbanska A. M., Saeb M. R., Venugopal J. R., Ramakrishna S., Mozafari M.: Electrospinning for tissue engineering applications. Progress in Materials Science, 117, 100721 (2021).

https://doi.org/10.1016/j.pmatsci.2020.100721

[10] Behari J.: Biophysical bone behavior. Principles and applications. Wiley, Chichester (2009).

[11] Yan Q. C., Tomita N., Ikada Y.: Effects of static magnetic field on bone formation of rat femurs. Medical engineering and physics, 20, 397-402 (1998).

https://doi.org/10.1016/s1350-4533(98)00051-4
[12] Aziz S. B., Woo T. J., Kadir M. F. Z., Ahmed H. M.: A conceptual review on polymer electrolytes and ion transport models. Journal of Science: Advanced Materials and Devices, 3, 1-17 (2018).

https://doi.org/10.1016/j.jsamd.2018.01.002

[13] Malikmammadov E., Tanir T. E., Kiziltay A., Hasirci V., Hasirci N.: PCL and PCL-based materials in biomedical applications. Journal of Biomaterials Science, Polymer Edition, 29, 863-893 (2018).

https://doi.org/10.1080/09205063.2017.1394711

[14] Kumar S., Jang J., Oh H., Jung B. J., Lee Y., Park H., Yang K. H., Seong Y. C., Lee J-S.: Antibacterial polymeric nanofibers from zwitterionic terpolymers by electrospinning for air filtration. ACS Applied Nano Materials, 4, 2375-2385 (2021).

https://doi.org/10.1021/acsanm.0c02366

[15] Aadil K. R., Mussatto S. I., Jha H.: Synthesis and characterization of silver nanoparticles loaded poly(vinyl alcohol)-lignin electrospun nanofibers and their antimicrobial activity. International Journal of Biological Macromolecules, 120, 763-767 (2018).

https://doi.org/10.1016/j.ijbiomac.2018.08.109

[16] El-Aassar M. R., Ibrahim O. M., Fouda M. M. G., ElBeheri N. G., Agwa M. M.: Wound healing of nanofiber comprising polygalacturonic/hyaluronic acid embedded silver nanoparticles: In-vitro and in-vivo studies. Carbohydrate Polymers, 238, 116175 (2020).

https://doi.org/10.1016/j.carbpol.2020.116175

[17] Akturk A., Taygun M. E., Goller G.: Optimization of the electrospinning process variables for gelatin/silver nanoparticles/bioactive glass nanocomposites for bone tissue engineering. Polymer Composites, 41, 24112425 (2020).

https://doi.org/10.1002/pc.25545

[18] Chou H. L., Wu C. M., Lin F. D., Rick J.: Interactions between silver nanoparticles and polyvinyl alcohol nanofibers. AIP Advances, 4, 087111 (2014).

https://doi.org/10.1063/1.4890290

[19] Arayanarakul K., Choktaweesap N., Aht-ong D., Meechaisue C., Supaphol P.: Effects of poly(ethylene glycol), inorganic salt, sodium dodecyl sulfate, and solvent system on electrospinning of poly(ethylene oxide). Macromolecular Materials and Engineering, 291, 581591 (2006).

https://doi.org/10.1002/mame.200500419

[20] Klairutsamee W., Supaphol P., Jangchud I.: Electrospinnability of poly(butylene succinate): Effects of solvents and organic salt on the fiber size and morphology. Journal of Applied Polymer Science, 132, 42716 (2015). https://doi.org/10.1002/app.42716

[21] Fan L., Xu Y., Zhou X., Chen F., Fu Q.: Effect of salt concentration in spinning solution on fiber diameter and mechanical property of electrospun styrene-butadienestyrene tri-block copolymer membrane. Polymer, 153, 61-69 (2018).

https://doi.org/10.1016/j.polymer.2018.08.008 
[22] Haider A., Haider S., Kang I-K.: A comprehensive review summarizing the effect of electrospinning parameters and potential applications of nanofibers in biomedical and biotechnology. Arabian Journal of Chemistry, 11, 1165-1188 (2018).

https://doi.org/10.1016/j.arabjc.2015.11.015

[23] Qin X-H., Yang E-L., Li N., Wang S-Y.: Effect of different salts on electrospinning of polyacrylonitrile (PAN) polymer solution. Journal of Applied Polymer Science, 103, 3865-3870 (2006).

https://doi.org/10.1002/app.25498

[24] Heikkilä P., Harlin A.: Electrospinning of polyacrylonitrile (PAN) solution: Effect of conductive additive and filler on the process. Express Polymer Letters, 3, 437445 (2009).

https://doi.org/10.3144/expresspolymlett.2009.53

[25] Shahreen L., Chase G. G.: Effects of electrospinning solution properties on formation of beads in $\mathrm{TiO}_{2}$ Fibers with $\mathrm{PdO}$ particles. Journal of Engineered Fibers and Fabrics, 10, 136-145 (2015).

https://doi.org/10.1177/155892501501000308

[26] Sumitha M. S., Shalumon K. T., Sreeja V. N., Jayakumar R., Nair S. V, Menon D.: Biocompatible and antibacterial nanofibrous poly( $\varepsilon$-caprolactone)-nanosilver composite scaffolds for tissue engineering applications. Journal of Macromolecular Science Part A, 49, 131-138 (2012). https://doi.org/10.1080/10601325.2012.642208

[27] Bittiger H., Marchessault R. H., Niegisch W. D.: Crystal structure of poly- $\varepsilon$-caprolactone. Acta Crystallographica Section B: Structural Crystallography and Crystal Chemistry, 26, 1923-1927 (1970). https://doi.org/10.1107/S0567740870005198

[28] Zidan H. M.: Effect of $\mathrm{AgNO}_{3}$ filling and UV-irradiation on the structure and morphology of PVA films. Polymer Testing, 18, 449-461 (1999). https://doi.org/10.1016/S0142-9418(98)00049-X

[29] Chandra S., Hashmi S. A., Saleem M., Agrawal R. C.: Investigations on poly ethylene oxide based polymer electrolyte complexed with $\mathrm{AgNO}_{3}$. Solid State Ionics, 67, 1-7 (1993). https://doi.org/10.1016/0167-2738(93)90301-I

[30] Song W., Mitchell G. R., Burugapalli K.: Electrospinning for medical applications. in 'Electrospinning: Principles, practice and possibilities' (ed.: Mitchell G. R.) Royal Society of Chemistry, Cambridge, 214-252 (2015). https://doi.org/10.1039/9781849735575-00214

[31] Bosworth L. A., Downes S.: Acetone, a sustainable solvent for electrospinning poly( $\varepsilon$-caprolactone) fibres: Effect of varying parameters and solution concentrations on fibre diameter. Journal of Polymers and the Environment, 20, 879-886 (2012).

https://doi.org/10.1007/s10924-012-0436-3

[32] Koombhongse S., Liu W., Reneker D. H.: Flat polymer ribbons and other shapes by electrospinning. Journal of Polymer Science Part B: Polymer Physics, 39, 25982606 (2001).

https://doi.org/10.1002/polb.10015
[33] Rashid T. U., Gorga R. E., Krause W. E.: Mechanical properties of electrospun fibers - A critical review. Advanced Engineering Materials, 23, 2100153 (2021). https://doi.org/10.1002/adem.202100153

[34] Kancheva M., Toncheva A., Manolova N., Rashkov I.: Enhancing the mechanical properties of electrospun polyester mats by heat treatment. Express Polymer Letters, 9, 49-65 (2015).

https://doi.org/10.3144/expresspolymlett.2015.6

[35] Chou S-F., Woodrow K. A.: Relationships between mechanical properties and drug release from electrospun fibers of PCL and PLGA blends. Journal of the Mechanical Behavior of Biomedical Materials, 65, 724733 (2017). https://doi.org/10.1016/j.jmbbm.2016.09.004

[36] Veleirinho B., Rei M. F., Lopes-da-Silva J. A.: Solvent and concentration effects on the properties of electrospun poly(ethylene terephthalate) nanofiber mats. Journal of Polymer Science Part B: Polymer Physics, 46, 460-471 (2008).

https://doi.org/10.1002/polb.21380

[37] Averous L., Moro L., Dole P., Fringant C.: Properties of thermoplastic blends: Starch-polycaprolactone. Polymer, 41, 4157-4167 (2000).

https://doi.org/10.1016/S0032-3861(99)00636-9

[38] Zhu H., Li R., Wu X., Chen K., Che J.: Controllable fabrication and characterization of hydrophilic PCL/wool keratin nanonets by electronetting. European Polymer Journal, 86, 154-161 (2017).

https://doi.org/10.1016/j.eurpolymj.2016.11.023

[39] Ferreira J. L., Gomes S., Henriques C., Borges J. P., Silva J. C.: Electrospinning polycaprolactone dissolved in glacial acetic acid: Fiber production, nonwoven characterization, and in vitro evaluation. Journal of Applied Polymer Science, 131, 410668 (2014).

https://doi.org/10.1002/app.41068

[40] Gu S-Y., Wu Q-L., Ren J., Vancso G. J.: Mechanical properties of a single electrospun fiber and its structures. Macromolecular Rapid Communications, 26, 716720 (2005).

https://doi.org/10.1002/marc.200400667

[41] Haider A., Haider S., Kang I-K.: A comprehensive review summarizing the effect of electrospinning parameters and potential applications of nanofibers in biomedical and biotechnology. Arabian Journal of Chemistry, 11, 1165-1188 (2018).

https://doi.org/10.1016/j.arabjc.2015.11.015

[42] Cooper C. J., Mohanty A. K., Misra M.: Electrospinning process and structure relationship of biobased poly(butylene succinate) for nanoporous fibers. ACS Omega, 3, 5547-5557 (2018). https://doi.org/10.1021/acsomega.8b00332

[43] Yao J., Jin J., Lepore E., Pugno N. M., Bastiaansen C. W. M., Peijs T.: Electrospinning of p-aramid fibers. Macromolecular Materials and Engineering, 300, 12381245 (2015). https://doi.org/10.1002/mame.201500130 
[44] Sadat-Shojai M.: Electrospun polyhydroxybutyrate/hydroxyapatite nanohybrids: Microstructure and bone cell response. Journal of Materials Science and Technology, 32, 1013-1020 (2016).

https://doi.org/10.1016/j.jmst.2016.07.007

[45] Young K., Blighe F. M., Vilatela J. J., Windle A. H., Kinloch I. A., Deng L., Young R. J., Coleman J. N.: Strong dependence of mechanical properties on fiber diameter for polymer-nanotube composite fibers: Differentiating defect from orientation effects. ACS Nano, 4, 6989-6997 (2010). https://doi.org/10.1021/nn102059c

[46] Croisier F., Duwez A-S., Jérôme C., Léonard A. F., van der Werf K. O., Dijkstra P. J., Bennink M. L.: Mechanical testing of electrospun PCL fibers. Acta Biomaterialia, 8, 218-224 (2012).

https://doi.org/10.1016/j.actbio.2011.08.015

[47] Ramazani S., Karimi M.: Aligned poly(e-caprolactone)/ graphene oxide and reduced graphene oxide nanocomposite nanofibers: Morphological, mechanical and structural properties. Materials Science and Engineering C, 56, 325-334 (2015).

https://doi.org/10.1016/j.msec.2015.06.045

[48] Naskar D., Bhattacharjee P., Ghosh A. K., Mandal M., Kundu S. C.: Carbon nanofiber reinforced nonmulberry silk protein fibroin nanobiocomposite for tissue engineering applications. ACS Applied Materials and Interfaces, 9, 19356-19370 (2017).

https://oi.org/10.1021/acsami.6b04777
[49] Yang F., Both S. K., Yang X., Walboomers X. F., Jansen J. A.: Development of an electrospun nano-apatite/PCL composite membrane for GTR/GBR application. Acta Biomaterialia, 5, 3295-3304 (2009). https://doi.org/10.1016/j.actbio.2009.05.023

[50] Yenier Z., Seki Y., Şen I., Sever K., Mermer Ö., Sarikanat M.: Manufacturing and mechanical, thermal and electrical characterization of graphene loaded chitosan composites. Composites Part B: Engineering, 98, 281-287 (2016).

https://doi.org/10.1016/j.compositesb.2016.04.072

[51] Karim L., Hussein A. I., Vaidya R., Morgan E. F., Bouxsein M. L.: The mechanical behavior of bone. in 'Marcus and Feldman's Osteoporosis' (eds.: Dempster D. W., Cauley J. A., Bouxsein M. L., Cosman F.) Elsevier, Cambridge, Vol. 1, 283-307 (2020).

[52] Keaveny T. M., Hayes W.: Mechanical properties of cortical and trabecular bone. in 'Bone' (ed.: Hall B. K.) Taylor and Francis, Bosa Roca, Vol. 7, 285-344 (1993).

[53] Fox B. S., Beyer M. K., Bondybey V. E.: Coordination chemistry of silver cations. Journal of the American Chemical Society, 124, 13613-13623 (2002). https://doi.org/10.1021/ja0176604

[54] Ratner M. A., Shriver D. F.: Ion transport in solventfree polymers. Chemical Reviews, 88, 109-124 (1988). https://doi.org/10.1021/cr00083a006 